\title{
Origen i reconstrucció paleoambiental dels jaciments d'icnites de fitanosaure de Fumanya
}

Josep Marmi (josep.marmi@icp.cat) Departament de Recerca de Faunes del Mesozoic. Institut Català de Paleontologia Miquel Crusafont (ICP, Sabadell)

Els jaciments de Fumanya (Berguedà) han estat tristament notícia degut a l'esllavissada del passat 10 de maig de 2016, que ha suposat una gran pèrdua patrimonial, científica i turística. Es tracta d'una basta superfície de roca on es poden observar milers de petjades de titanosaure juntament amb restes vegetals corresponents a palmeres i coníferes extingides. Aquests jaciments representen la base de la Formació Tremp, que registra l'evolució dels ambients transicionals-continentals del nord-est d'lbèria al llarg dels darrers sis milions d'anys de l'era mesozoica. L'estudi de les petjades de titanosaure i dels fòssils de plantes ha permès conèixer aspectes interessants sobre l'ambient on vivien aquests dinosaures gegantescos i de la seva paleoecologia. A partir d'aquestes dades podem imaginar que els titanosaures caminaven per planes fangoses inundades i que es concentraven als marges de llacs d'aigua dolça on possiblement s'alimentaven de fulles de falgueres $i$ palmeres o brots de coníferes arbustives. La presència d'alguns rastres paral-lels demostraria que aquests animals tenien un cert comportament social.

Paraules clau: Fumanya, icnites, titanosaures, Maastrichtià, Formació Tremp

The Fumanya megatrack sites (Berguedà) has been unfortunately in the news due to a landslide occurred on $10^{\text {th }}$ may 2016, which has resulted in a great loss in terms of heritage, science and tourism. These megatrack sites cosist of a vast rock surface showing thousands of titanosaur footprints with plant remains assigned to palms and extinct conifers. These sites correspond to the base of the Tremp Formation, which records the evolution of the northeastern Iberia transitional to continental environments throughout the last six millions of years of the Mesozoic era. The study of titanosaur footprints as well as plant fossils revealed interesting issues about the environment where these huge dinosaurs inhabited and their paleoecology. Based on these data, we are able to imagine titanosaurs walking on mudflats and concentrated at the margins of freshwater lakes where they probably fed on fern and palm leaves as well as conifer shoots. Several parallel trackways would demonstrate that these animals developed some social behaviour.

Keywords: Fumanya, ichnites, titanosaurs, Maastrichtian, Tremp Formation

\footnotetext{
"Una esllevissada destrossa les petjades de Fumanya", "Una esllavissada destrueix 30 metres del jaciment de dinosaures de Fumanya", "Un expert va avisar fa dotze anys del risc de perdre les petjades si no s'hi intervenia", etc., anunciaven diferents diaris, televisions i ràdios els passats 16 i 17 de maig de 2016.
}

Les intenses pluges dels dies anteriors, així com la gran inclinació del terreny van propiciar una gran esllavissada (figura 1), que ha afectat a una superfície de roca del jaciment de Fumanya sud, la qual conté centenars de petjades i desenes de rastres de titanosaure. A l'espera d'un diagnòstic més acurat, es tracta d'una gran pèrdua irreparable. 
Però què són els jaciments de Fumanya? Quin ha estat el seu interès geològic i paleontològic, reconegut internacionalment? Com ens ajuda a entendre com era la vida a la regió pirinenca fa milions d'anys?

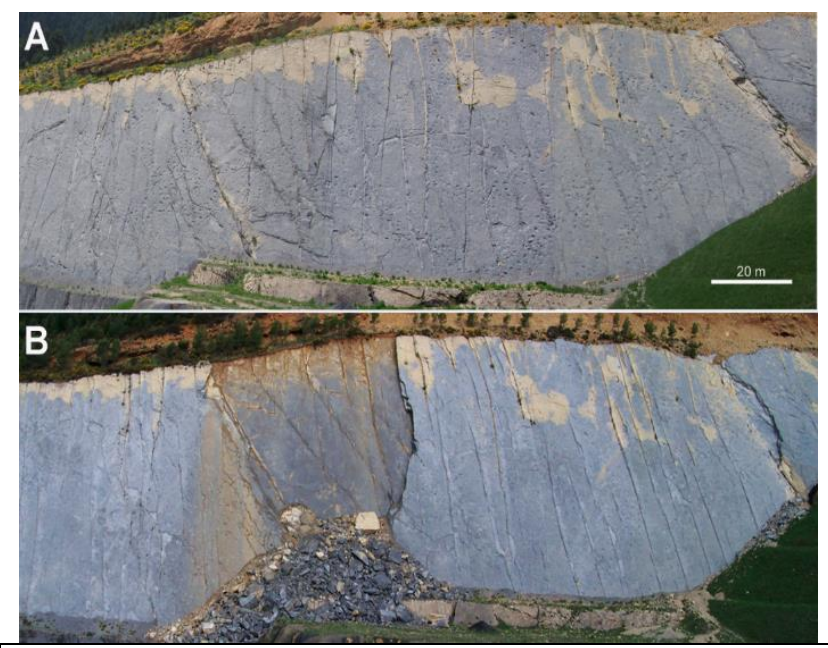

Figura 1. Imatge del jaciment de Fumanya sud abans (A) i després (maig del 2016, B) de l'esllavissada.

\section{L'ORIGEN DE LA CONCA ON VAN VIURE ELS DINOSAURES DELS PIRINEUS}

Fa uns 72 milions d'anys, una mar tropical que submergia la zona on actualment trobem els Pirineus es va començar a enretirar cap a l'oest. El paisatge marí va evolucionar cap a una extensa plana fangosa d'uns $2.500 \mathrm{~km}^{2}$, inundada per aigües salabroses (Oms et al., 2016). Sota les aigües que cobrien aquesta basta conca, orientada d'est a oest (Figura 1), el fang es combinava amb el carbonat càlcic que precipitava fins a formar un tipus de roca anomenada calcària margosa. La capa de roca resultant fa una mitjana d'uns cinc metres de gruix i la podem trobar des del massís del Catllaràs (el Berguedà) fins a Isona (el Pallars Jussà) i, cap al sud, fins a Figuerola de Meià (la Noguera) (Oms et al., 2016). Els miners la van batejar com a 'nivell dels ciments', doncs la calcària margosa era utilitzada en la fabricació d'aquest material de construcció. Recentment, els geòlegs I'han anomenat Membre Fumanya i forma la base del que coneixem com a Formació Tremp, tot un conjunt de capes de roques d'origen sedimentari que registren la història dels darrers dinosaures que van habitar el nord-est d'lbèria.

En realitat, l'origen de les roques que constitueixen el Membre Fumanya va ser uns $100 \mathrm{~km}$ més al nord d'on es troben ara, en una zona equivalent a on ara trobaríem l'extrem nord del Pallars Sobirà i Andorra (Figura 2). Tot un seguit de desplaçaments d'enormes mantells de roca cap al sud, fruit de la formació dels Pirineus, van transportar i trencar les roques del Membre Fumanya, a demés de les capes de roques més recents que les cobreixen, cap a la seva localització actual.

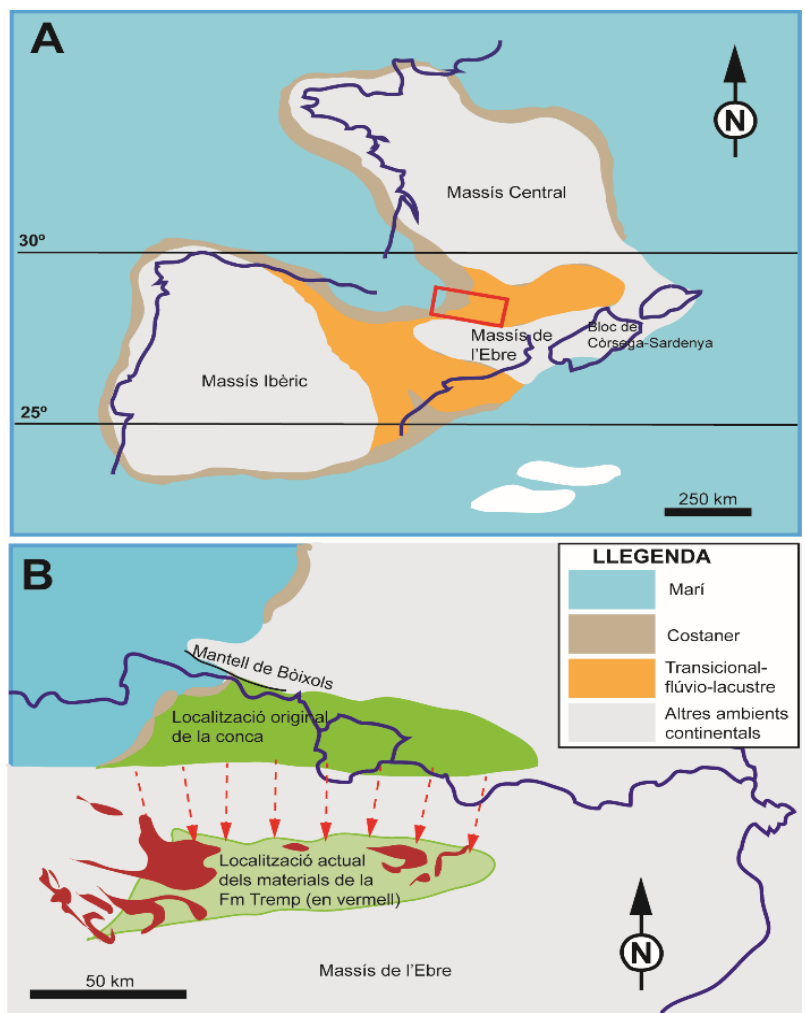

Figura 2. A, Mapa paleogeogràfic de l'illa Iberoarmoricana que va existir a finals del Cretaci a la part més occidental de l'arxipèlag europeu. Estava formada per les terres emergides d'lbèria, part de França i Sardenya. B, Detall de la conca sud-pirinenca (requadre en $A$ ) mostrant la seva posició original a finals del Cretaci (verd) i la localització actual de les roques que s'hi van formar (vermell), després de ser transportades cap al sud a causa de la formació dels Pirineus.

Al Berguedà, concretament als municipis de Fígols, Vallcebre i Saldes, el naixement de la serra d'Ensija va deformar les roques de la Formació Tremp fins a posar-les gairebé en posició vertical. Els treballs de la mineria a cel obert realitzats a la zona durant la dècada dels 1980s van exposar aquests estrats a la base d'Ensija. Aquí, fruit dels processos naturals i de l'activitat minera de l'home, la superfície de les calcàries margoses del Membre Fumanya ens apareix com un reguitzell d'espectaculars parets que en total sumen uns $35.000 \mathrm{~m}^{2}$ i que corresponen als jaciments de Fumanya sud (Fígols), Mina Esquirol, Fumanya nord i Mina Tumí (Vallcebre) (Vila et al., 2008; Figura 1). Al llarg de totes 
aquestes parets, els paleontòlegs han comptabilitzat més de 3.000 petjades i uns 50 rastres de titanosaures, un grup de dinosaures sauròpodes de dimensions gegants, coll i cua allargats i malucs amples que es van diversificar durant el període Cretaci, fa entre 145 i 66 milions d'anys.

\section{UNA DESCOBERTA INESPERADA SE- GUIDA D'UN OBLIT TEMPORAL}

El 31 de març de 1985, en Lluís Viladrich i Pons i na Montserrat Gorchs i Corominas, professors de secundària i membres del Col-lectiu Berguedà de Ciències Naturals, estaven fent una catalogació de plantes pels voltants de les explotacions de carbó a cel obert de Fumanya. De sobte, en Lluís es va fixar en un seguit de clots disposats en fileres paral-leles que apareixien a la superfície de la paret de roca de Fumanya sud. A partir d'un examen més detallat $\mathrm{i}$ dels seus coneixement de la geologia local, Viladrich va sospitar que podia tractar-se de petjades de dinosaure. Seguidament, va contactar amb els especialistes en dinosaures de l'Institut Paleontològic de Sabadell, els Drs. Josep Vicens Santafé i Lourdes Casanovas, els quals no van visitar les petjades de Fumanya sud fins gairebé un any després de la descoberta, confirmant aleshores les sospites d'en Lluís. El mateix any, en Viladrich publicava la primera descripció de les petjades i rastres de dinosaure a la revista comarcal L'Erol (Viladrich, 1986).

Malgrat el seu potencial, el jaciments de Fumanya van caure gairebé en l'oblit durant la dècada dels 1990s. Tan sols el paleontòleg francès Jean Le Loeuff i el geòleg català Albert Martínez-Rius van fer una descripció molt preliminar d'alguns rastres localitzats a l'extrem nord de Fumanya sud $i$ els icnòlegs Anne Schulp i Wouter Brokx, del Museu de Ciències Naturals de Maastricht, van fer una primera cartografia general del jaciment (Le Loeuff i MartínezRius, 1997; Schulp i Brokx, 1999). Va caldre esperar fins a principis dels 2000 s perquè comencés a sortir a la llum la importància real dels jaciments de Fumanya, els quals són únics a Europa i, a nivell mundial, només se n'han documentat dos més de similars a Bolívia, anomenats Toro Toro i Cal Orcko (Vila et al., 2008). Al llarg d'aquesta dècada, la recerca liderada per investigadors de l'Institut Català de Paleontologia Miquel Crusafont, de les universitats de BarceIona i Autònoma de Barcelona, juntament amb col-laboracions internacionals amb les universitats de Manchester (Regne Unit) i Claude Bernard de Lyon (França), s'ha intensificat a la zona. Tot això ha permès conèixer l'edat del jaciment (Oms et al., 2007), realitzar una cartografia digital de les petjades mitjançant la tecnologia LiDAR (Light Detection and Range; Bates et al., 2008), estudiar amb gran detall les petjades i rastres (Vila et al., 2013; Castanera et al., 2014), reconstruir amb força precisió l'ambient i proposar hipòtesis sobre la vegetació que creixia a la zona i sobre com vivien els titanosaures en aquells entorns (Marmi et al., 2014).

La preservació del jaciment, però, ha estat una constant assignatura pendent en tota aquesta història (Vila et al., 2006). La disposició gairebé vertical de les parets de roca que fa evident la seva espectacularitat, també n'és el seu tendó d'Aquil.les. A tot això s'hi afegeix la seva localització a 1.500 metres d'altitud, la constant exposició a l'intempèrie, les infiltracions d'aigües $i$ els episodis de glaçades i desglaçades. Durant les dècades dels 80 s i 90 s, les empreses que tenien la titularitat de l'explotació minera no es van fer responsables dels treballs de restauració i conservació del jaciment. D'altra banda, tot i que el conjunt paleontològic de Fumanya va ser declarat Bé Cultural d'Interès Nacional per la Generalitat de Catalunya l'any 2005, no s'han fet les degudes intervencions necessàries per garantir la seva preservació, malgrat que des del mateix any existeix un projecte d'enginyeria, encarregat pels municipis de la zona, on s'explica clarament quines eren les primeres mesures a prendre per evitar la seva degradació. Després de més d'una dècada i fruit de l'abandonament del jaciment, el 10 de maig de 2016, uns $2.000 \mathrm{~m}^{2}$ de paret de Fumanya sud es van esllavissar, perdent-se desenes de petjades i deixant una cicatriu enorme en un jaciment de gran interès patrimonial, científic i turístic (Figura 2). Aquesta esllavissada és el detonant de la destrucció de Fumanya que d'aquí a deu anys més encara pot ser molt més gran si no es fa res per evitar-ho.

\section{RECONSTRUÏT UN AMBIENT PERDUT}

El paisatge de la zona de Fumanya de fa alguns centenars o milers d'anys possiblement ens resultaria força familiar encara. Les principals diferències serien majoritàriament degudes a la intervenció humana, especialment pels efectes de l'activitat minera i l'aprofitament dels boscos de la zona. No obstant, el paisatge actual de Fumanya no conserva cap semblança amb el que era fa 72 milions d'anys enrere. Aleshores, com podem reconstruir l'aspecte d'aquells ambients pretèrits? Afortunadament, ens n'han quedat pistes en les diferents capes roques sedimentàries que hem estudiat, les quals ens ajuden a explicar la història dels darrers milions d'anys de l'era dels dinosaures com si estiguéssim llegint les planes d'un llibre. Ens centrarem, però, en les calcàries margoses de Fumanya (base de la Formació Tremp) i de les primeres capes de roca que les 
cobreixen, ja que són les que contenen les petjades de titanosaure.

Com s'ha dit anteriorment, el gruix del Membre Fumanya és d'uns 5 metres, la qual cosa ha permès calcular que els fangs que van donar lloc a aquestes roques es van estar dipositant al llarg d'uns 100.000 anys (Marmi et al., 2008). La coloració grisenca de la roca i l'absència d'esquerdes de dessecació ens suggereix que aquests sediments estaven permanentment coberts d'aigua.

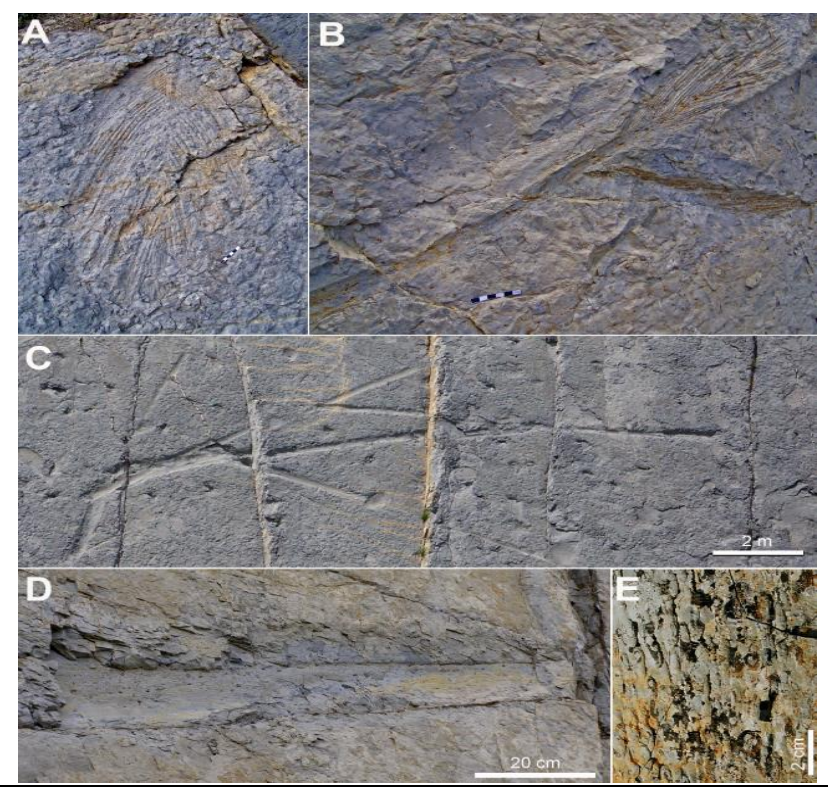

Figura 3. Impressions de fulles (A i B) i troncs (C i D) de la palmera Sabalites longirhachis. E, Detall de la base d'un tronc on es poden observar marques d'arrels adventícies, típiques de les palmeres.

Al llarg de la secció d'aquestes calcàries margoses, s'han trobat alguns nivells amb abundants fòssils de mol-luscs (ostres, petxines, cargols) i petits crustacis (ostràcodes) tolerants de salinitats variables a més a més de dents i agullons caudals de rajades, la qual cosa indicaria que aquelles aigües tindrien una salinitat entre baixa i moderada, sense arribar a la de l'aigua de mar. Evidències geològiques de marees, però, testimonien que hi podria haver hagut una certa influència marina en alguns moments (Riera et al., 2010). D'altra banda, les roques del Membre Fumanya estan cobertes per la capa de carbó més basal que suggereix un ambient més típic d'aigua dolça al final del seu procés de sedimentació.

Tot aquests tipus d'evidències donen suport a la hipòtesi que l'ambient on es van formar aquestes roques i les de les capes següents era aquàtic, proper a la mar i que podia presentar fluctuacions de salinitat moderades (Villalba-Breva et al., 2012). És el que coneixem com un ambient transicional, típic de zones amb aiguamolls costaners.

Les petjades de titanosaure es concentren entre la part superior del Membre Fumanya i la base de la primera capa de carbó de la sèrie. Això suggereix que part d'aquella extensa plana fangosa s'estava convertint en una torbera quan els gegantescos titanosaures s'hi passejaven. Quins tipus de plantes van originar aquest carbó i d'on provenien les seves restes? A part de petjades i rastres de titanosaure, les superfícies de Fumanya conserven restes vegetals molt interessants. S'hi han identificat més de 80 fulles i prop d'un centenar de motlles de troncs d'una palmera primitiva anomenada Sabalites longhirhachis a més a més de grans acumulacions de branquillons d'una conífera extingida anomenada Frenelopsis (Marmi et al., 2010; Figures 3 i 4). La quantitat de restes vegetals era tan gran que segurament cobria la superfície fangosa com si fos una catifa i aquestes restes serien la matèria primera del carbó que s'ha explotat a la zona.

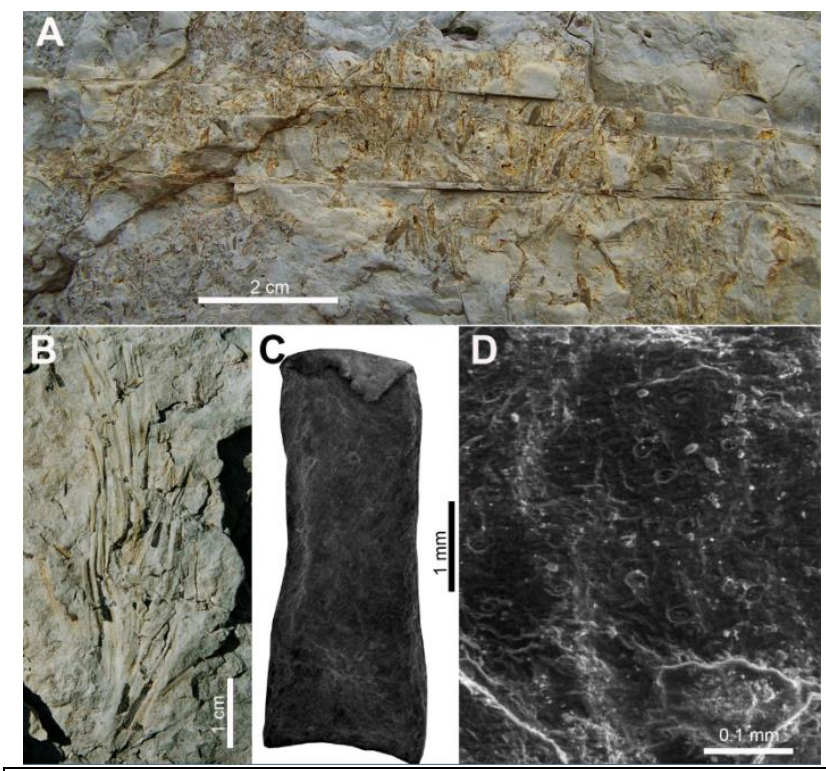

Figura 4. Restes de la conífera Frenelopsis sp. A, Acumulació de restes de branquillons. B, Branquillons ramificats en connexió anatòmica. C, Detall d'un branquilló fotografiat en un microscopi electrònic. D, Imatge magnificada de $C$ on es poden observar línies paral-leles d'estomes que són característiques d'aquest gènere de coníferes extingides.

No s'han trobat marques d'arrels fòssils a la mateixa superfície la qual cosa suggereix que les plantes productores no creixien en l'ambient de dipòsit, sinó que les seves restes hi van ser transportades, 
flotant per les aigües dels aiguamolls propers als marges de la plana fangosa (Villalba-Breva et al., 2012). El bon estat de conservació d'aquests fòssils, però, ens fa pensar que les palmeres i les coníferes Frenelopsis devien créixer en ambients propers. La descoberta de marques d'arrels, algunes atribuïdes a palmeres, a la part superior de calcàries d'origen lacustre, uns metres per sobre de la superfície amb petjades i restes vegetals, indicaria que les úniques zones vegetades dels aiguamolls eren els marges de llacs d'aigua dolça. Aquesta darrera hipòtesi ha estat confirmada per l'abundància de fòssils d'unes algues verdes d'aigua dolça anomenades caròfits en les calcàries que tenen fòssils d'arrels. En mostres recollides en aquests mateixos nivells s'han identificat també espores de diferents espècies de falgueres.

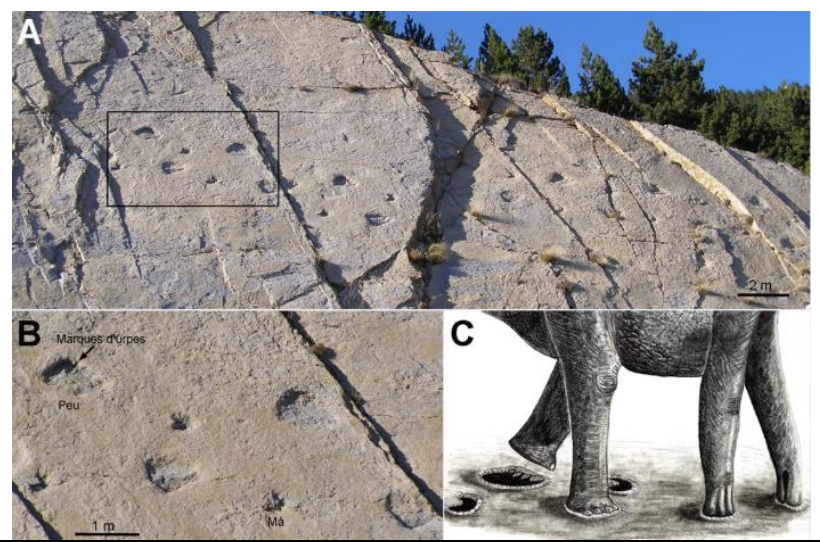

Figura 5. A, Imatge de Pedra Ronyosa (sector nord de Fumanya sud) on es pot observar un rastre de titanosaure. B, Detall del rastre anterior (requadre en A) on es pot apreciar la diferència de forma i mida de les petjades de mans i peus i la distància moderada entre les petjades de les extremitats esquerres i dretes. C, Reconstrucció ideal d'un titanosaure fent el rastre anterior.

\section{QUĖ ENS EXPLIQUEN LES PETJADES DE FUMANYA SOBRE LA VIDA DELS TI- TANOSAURES?}

En els jaciments de Fumanya, hem identificat fins a sis nivells més amb petjades, a part de les que hi ha a la superfície de roca del Membre Fumanya. Totes les petjades i rastres s'han atribuït a dinosaures sauròpodes del grup dels titanosaures a partir de les següents característiques (Vila et al., 2008; Figura 5): 1) petjades de les mans en forma de mitja lluna $i$ sense marques de urpes, 2) petjades dels peus el triple de grans que les de les mans, amb forma subtriangular $\mathrm{i}$, en alguns casos, conservant les marques de fins a quatre urpes, 3 ) petjades de mans i peus lleugerament rotades cap enfora del rastre, 4) amplada gran entre les petjades de les extremitats esquerres i dretes. Les anàlisis de diferents variables mesurades en les petjades i rastres indiquen que els animals productors podien fer més de 20 metres de longitud i que caminaven a poc a poc (entre 2,5 i $3,7 \mathrm{~km} / \mathrm{h}$ ) (Vila et al., 2013).

Les dades recopilades a Fumanya també han permès conèixer millor la diversitat d'hàbitats on vivien aquests enormes dinosaures així com altres aspectes de la seva paleoecologia. A partir de les anàlisis de les dades obtingudes de jaciments d'arreu del món, alguns investigadors han plantejat que els titanosaures habitaven ambients fluvials i lacustres allunyats del mar, mentre que altres grups de sauròpodes eren més típics d'ambients costaners i deltaics (Mannion i Upchurch, 2010). Les petjades de les parets de Fumanya demostren, però, que alguns titanosaures freqüentaven ambients propers a la costa $i$ han permès distingir entre dos patrons de comportament ben diferenciats (Marmi et al., 2014). A la superfície de margocalcària del Membre Fumanya, la densitat de petjades és baixa $(\sim 0,11$ petjades $\left./ \mathrm{m}^{2}\right)$ i els rastres es poden distingir fàcilment ( $\mathrm{Fi}$ gura 6 ).

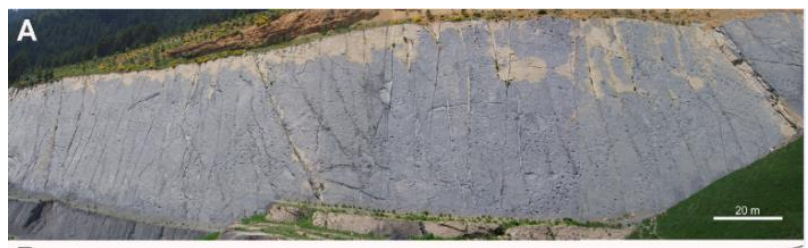

B
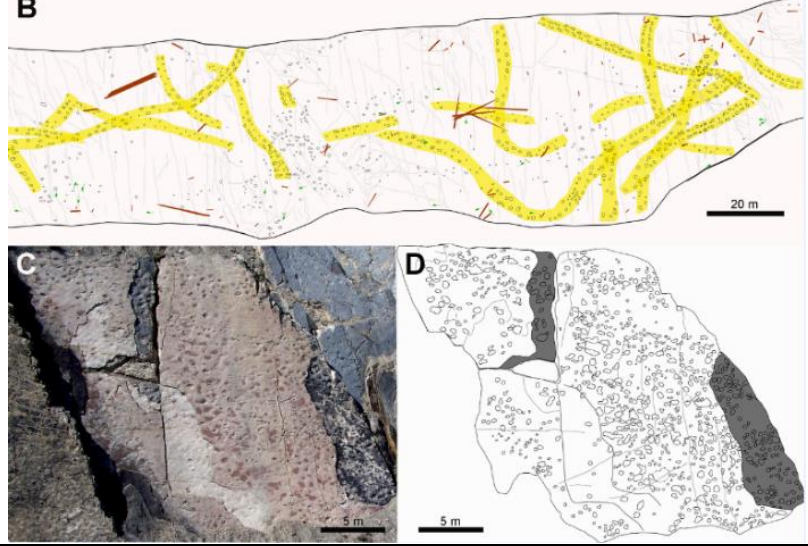

Figura 6. Imatge (A) i mapa (B) de la superfície de les calcàries margoses de Fumanya sud on s'han marcat les petjades, rastres (resseguits en groc), impressions de troncs (marró) i de fulles (verd) de palmera. Fotografia (C) i mapa (D) de la superfície d'uns nivells de calcària superiors, al jaciment de Fumanya nord, on es pot observar una gran densitat de petjades de titanosaure. 
Sovint aquests rastres estan orientats a l'atzar i a vegades es creuen entre ells la qual cosa suggereix que podien haver sigut produïts per animals solitaris movent-se erràticament. En altres casos es poden distingir rastres paral-lels $\mathrm{i}$ allargats que indicarien un cert comportament gregari (Figura 6). En conjunt, l'escenari més probable seria una multitud d'individus desplaçant-se sense un objectiu preferencial al llarg d'una plana fangosa inundada i sense vegetació.

Al jaciment de Fumanya nord, a uns vuit metres sobre el nivell anterior, apareix una superfície de roca calcària d'uns $600 \mathrm{~m}^{2}$ que està farcida de petjades, arribant a una densitat d'unes 1,66 petjades $/ \mathrm{m}^{2}$, la qual cosa fa impossible distingir-hi rastres (Figura 6). L'alta concentració de petjades d'aquesta superfície s'ha interpretat com una congregació de molts individus en una àrea que podia haver estat relativament petita. La calcària és d'origen lacustre $\mathrm{i}$ conserva fòssils d'algues caròfites d'aigua dolça a més a més de marques d'arrels de plantes. A partir de l'alta densitat de petjades de titanosaure i de les evidències de creixement de vegetació hem proposat la hipòtesi que els marges d'alguns llacs d'aigua dolça en els aiguamolls costaners de la conca pirinenca podrien haver estat zones d'alimentació dels ramats de titanosaures.

En resum, l'estudi dels jaciments de petjades de titanosaure de Fumanya ha permès demostrar que aquests grans sauròpodes podien viure en una major diversitat d'hàbitats del que pensàvem, incloent ambients més interiors (fluvials) i zones d'aiguamolls costaners. Els titanosaures possiblement rastrejaven aquests ambients costaners a la recerca de la vegetació que creixia als marges de llacs d'aigua dolça i que possiblement consistia en falgueres, arbusts de la conífera Frenelopsis i palmeres. En copròlits (femta fòssil) de titanosaures descoberts a I'Índia s'han trobat restes d'aquestes plantes (Prasad et al., 2005), la qual cosa reforçaria la nostra interpretació.

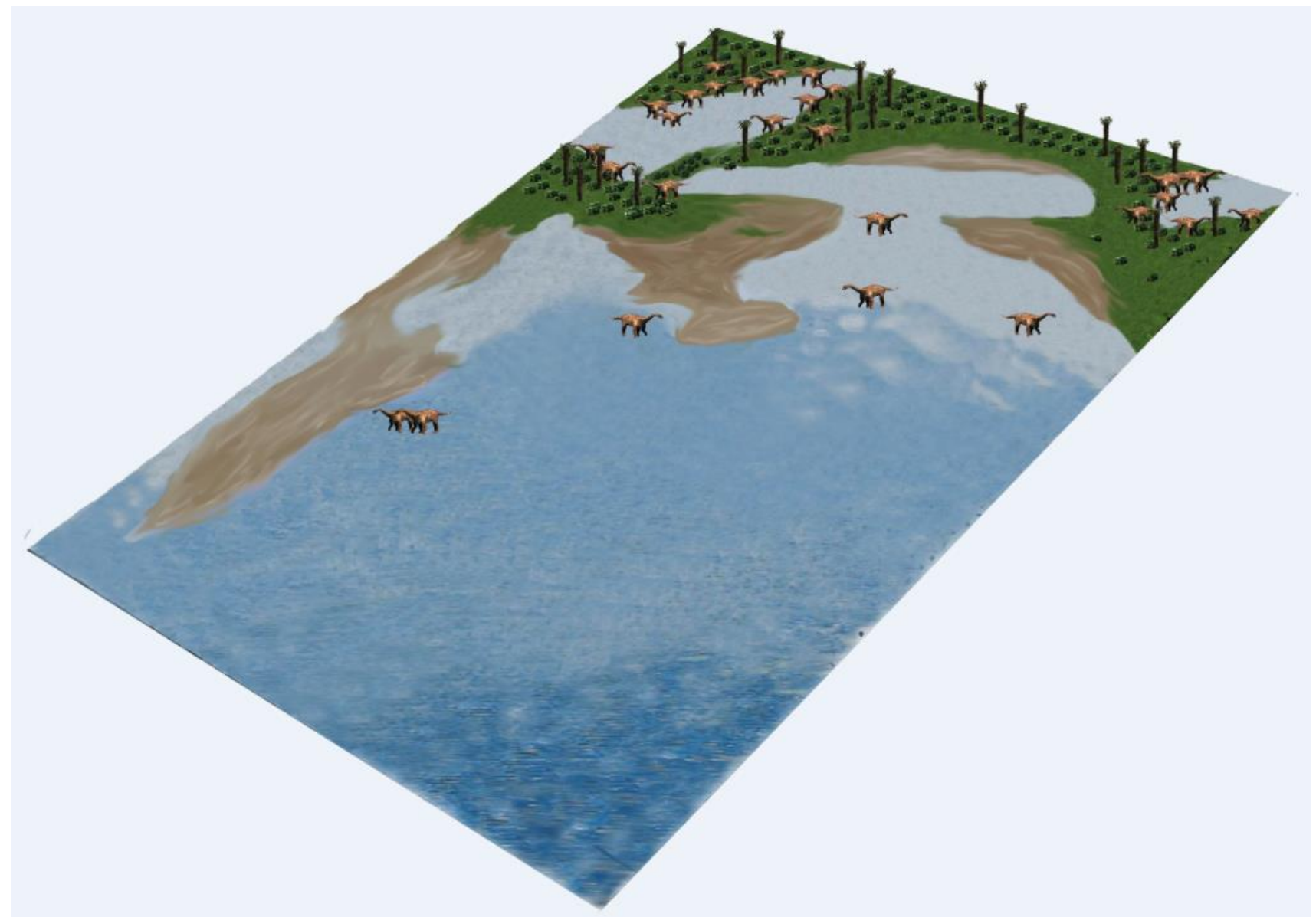

Figura 7. Reconstrucció ideal del paisatge de la zona pirinenca quan es van dipositar els materials de la unitat grisa de la Formació Tremp en ambients d'aiguamolls costaners. Els titanosaures deambulaven per les zones no vegetades de la plana fangosa i es concentraven als marges dels llacs d'aigua dolça, on probablement anaven a menjar plantes que hi creixien. 


\section{AGRAIIMENTS}

Agraeixo als col-legues Bernat Vila i Àngel Galobart (ICP) i Oriol Oms (UAB) la revisió crítica que han fet del manuscrit.

\section{BIBLIOGRAFIA}

BATES, K.T., RARITY, F., MANNING, P.L., HODGETTS, D., VILA, B., OMS, O., GALOBART, À., GAWTHORPE, R.L. (2008). High-resolution LiDAR and photogrammetric survey of the Fumanya dinosaur tracksites (Catalonia): implications for the conservation and interpretation of geological heritage sites. Journal of the Geological Society, 165, pp. 115-127.

CASTANERA, D., VILA, B., RAZZOLINI, N., SANTOS, V.F., PASCUAL, C., CANUDO, J.I. (2014). Sauropod trackways of the Iberian Peninsula: palaeoetological and palaeoenvironmental implications. Journal of Iberian Geology, 40, pp. 4959.

LE LOEUFF, J., MARTÍNEZ-RIUS, A. (1997). Afloramiento de icnitas de Titanosauridae en la zona de Fumanya (Maastrichtiense, Pirineo oriental): estudio preliminar. Geogaceta, 21, pp. 151-153.

MANNION, P.D., UPCHURCH, P. (2010). A quantitative analysis of environmental associations in sauropod dinosaurs. Paleobiology, 36, pp. 253282.

MARMI, J., MALCHUS, N., VILA, B., POZA, B., RIERA, V., GALOBART, Â., OMS, O., GOMEZ, B., MARTÍN-CLOSAS, C. (2008). Where dinosaurs got wet feet - wetland fauna and flora associated to titanosaur tracks in the southeastern Pyrenees. TAPHOS'08 Abstracts volume, p. 64.

MARMI, J., GOMEZ, B., MARTÍN-CLOSAS, C., VILLALBA-BREVA, S. (2010). A reconstruction of the fossil palm Sabalites longirhachis (Unger) J. Kvaček et Herman from the Maastrichtian of Pyrenees. Review of Palaeobotany and Palynology, 163, pp. 73-83.

MARMI, J., VILA, B., MARTÍN-CLOSAS, C., VILLALBA-BREVA, S. (2014). Reconstructing the foraging environment of the latest titanosaurs (Fumanya dinosaur tracksite, Catalonia). Palaeogeography, Palaeoclimatology, Palaeoecology, 410, pp. 380-389.

OMS, O., DINARÈS-TURELL, J., VICENS, R., ESTRADA, M., VILA, B., GALOBART, À., BRAVO, A.M. (2007). Integrated stratigraphy from the
Vallcebre Basin (southeastern Pyrenees, Spain): new insights on the continental Cretaceous-Tertiary transition in southwest Europe. Palaeogeography, Palaeoclimatology, Palaeoecology, 255, pp. 35-47.

OMS, O., FONDEVILLA, V., RIERA, V., MARMI, J., VICENS, E., ESTRADA, R., ANADÓN, P., VILA, B., GALOBART, À. (2016). Transitional environments of the lower Maastrichtian south-Pyrenean Basin (Catalonia, Spain): the Fumanya Member tidal flat. Cretaceous Research, 57, pp. 428-442.

PRASAD, V., STRÖMBERG, C.A.E., ALIMOHAMMADIAN, H., SAHNI, A. (2005). Dinosaur coprolites and the early evolution of grasses and grazers. Science, 310, pp. 117-118.

RIERA, V., MARMI, J., OMS, O., GOMEZ, B. (2010). Orientated plant fragments revealing tidal paleocurrents in the Fumanya mudflat (Maastrichtian, southern Pyrenees): insights in palaeogeographic reconstructions. Palaeogeography, Palaeoclimatology, Palaeoecology, 288, pp. 82-92.

SCHULP, A.S., BROKX, W.A. (1999). Maastrichtian sauropod footprints from the Fumanya site, Berguedà, Spain. Ichnos, 6, pp. 239-250.

VILA, B., OMS, O., GALOBART, À., VICENS, E., VILADRICH, L., RIBERA, J. (2006). Síntesis fotográfica de la degradación del patrimonio paleontológico en el yacimiento de Fumanya (Berguedà, Barcelona). Dins Rábano, I., Mata-PereIló, J.M. (Eds) Patrimonio Geológico y Minero: su caracterización y puesta en valor. Cuadernos del Museo Geominero, 6, pp. 511-516.

VILA, B., OMS, O., MARMI, J., GALOBART, À. (2008). Tracking Fumanya footprints (Maastrichtian, Pyrenees): historical and ichnological overview. Oryctos, 8, pp. 117-130.

VILA, B., OMS, O., GALOBART, À., BATES, K.T., EGERTON, V.M., MANNING, P.L. (2013). Dynamic Similarity in Titanosaur Sauropods: Ichnological Evidence from the Fumanya Dinosaur Tracksite (Southern Pyrenees). PLOS ONE, 8, e57408.

VILLALBA-BREVA, S., MARTÍN-CLOSAS, C., MARMI, J., GOMEZ, B., FERNÁNDEZ-MARRÓN, M.T. (2012). Peat-forming plants in the Maastrichtian coals of the Eastern Pyrenees. Geologica Acta, 10, pp. 189-207.

VILADRICH, L. (1986). Les petjades fossils del Coll de Fumanya. L'Erol, 18, pp. 7-12. 